\title{
Research on Ambiguity in English Learning Shu-kuan $\mathrm{LU}^{1, \mathrm{a},{ }^{*}}$ \\ ${ }^{1}$ Eastern Liaoning University, Liaoning Province, China \\ alushukuan1966@163.com
}

Keywords: Ambiguity, Subjunctive mood, Polysemy, Idiom, Ambiguity tolerance.

\begin{abstract}
Ambiguity is a kind of linguistic phenomenon. It is a barrier for English learners to get exact information. It mainly appears in voice, grammar and vocabulary. Many researchers have expounded the phenomenon. This paper lays particular emphasis on grammatical structure, subjunctive mood, polysemants and idioms and their causes. English learners are expected to improve their cognitive ability and ambiguity tolerance, and adopt positive attitude to remove ambiguity so as to learn English efficiently.
\end{abstract}

\section{Introduction}

When a sentence or a word or a phrase has two or at least two different or relevant meanings, this phenomenon is semantically called ambiguity. Ambiguity is a complicated but universal language phenomenon, which exists in every language. Ambiguity in English language is a kind of barrier for learners to get the information exactly, which ends up with low efficient learning. This paper analyzes the causes of ambiguity in grammar and vocabulary, and introduces the countermeasure to the ambiguity.

\section{Grammatical Ambiguity}

Different languages entail different grammars, which causes trouble to foreign language learners learn language usage of the target language, hence ambiguity appears. Much ambiguity exists in English grammar, esp. in complicated sentence structures and subjunctive mood, which cause the English learners to feel lost.

\section{Grammatical Ambiguity Caused by Complicated Sentence Structures}

Complicated sentence structure means that a sentence has more elements than the readers could recognize easily.

A strong economy, cheap land on the urban fringe, the desire for single homes on large lots, increased automobile ownership, the second cheapest gasoline in the world, good roads provided from the public purse, and urban planning that forced work places, all combined to create the famous "urban sprawl" and "commuter rush hour" which are characteristic of North American cities [1].

The sentence above as an example has seven subjects, and the following sentence has six predicates.

China now enjoys the MFN status with American, is the biggest exporter of consumer goods to that market, has amassed a trade surplus of over a trillion dollars, has a huge export driven economy and an industrial base provides employment to its people and raise their per capita income, has achieved world's highest growth rate and is rapidly achieving a qualitative edge in the manufacturing sector [2]. 


\section{Grammatical Ambiguity Caused by Subjunctive Mood}

Subjunctive mood is not a peculiar item in Chinese grammar, which not only signifies the contradiction against the fact but also expresses the speakers' wish that cannot come true. Subjunctive mood is achieved through complicated forms of predicate verbs which results in difficulty for English learners to get the speaker's idea.

\section{Contrary to the Present Fact}

I have often thought it would be a blessing if each human being were stricken blind and deaffor a few days at some time during his early adult life. Darkness would make him more appreciative of sight; silence would teach him the joys of sound [3].

\section{Contrary to the Past Fact}

"If he had known about the win I would never have known whether it was me or the money he would want to stay with," she said, "I don't know what I would have done if he hadn't answered yes. I love him and want to enjoy spending the money with him."

Contrary to the Future

Sometimes I have thought it would be an excellent rule to live each day as if we should die tomorrow. Such an attitude would emphasize sharply the values of life [4].

\section{Blended Time}

Subjunctive mood confuses English learners, and even frustrates the learners when time in one sentence is blended.

a. If I had not studied English, I would never be here to teach you grammar today.

b. If they had invested in that stock, they might be wealthy now.

\section{Other Special Expressions for Subjunctive Mood}

Some structures are not typical subjunctive mood structures, but they play the roles of subjunctive mood.

a. But for their help, I would not have finished the task.

b. What I would have done without you?

c. Anyone in his position would have done it like that.

d. I didn't know the extent of his difficulty, or else I would have promised to help him.

e. If only he had followed your advice!

\section{Grammatical Ambiguity Caused by the Structure Modal Verb + Perfective}

Modal verb + perfective is a way to express speculation and blame, which is hardly understandable to the learners.

Expressing Speculation

a. A: The money has disappeared! Who could have taken it?

B: John could have; he was here alone yesterday.

b. You screamed in your sleep last night. You must have had a terrible dream.

c. I can't find my sunglasses. I may/might have left them at the restaurant yesterday.

Expressing Blame

a. You should have phoned me last night.

b. A: I feel terribly ill today.

B: You shouldn't have eaten those mushrooms yesterday. Mushrooms don't agree with you.

c. You could have told me you were getting married. 


\section{Vocabulary Ambiguity Caused by Polysemy}

A word always symbolizes a specific object or phenomenon as it was initially invented; hence this word has a single meaning originally. With development of society, the way of one-to-one correspondence has no longer satisfied new objects and phenomena unceasingly appearing. As a result, more meanings are endowed to the existent words with the help of some means. Such kind of word is traditionally called polysemant. This phenomenon is called ambiguity which causes trouble to English learners. In English, large part of vocabulary is polysemants.

Through analyzing the meanings of polysemants, we can find that meaning of a word has certain relations, which are primary meaning and derivative meaning, universal meaning and special meaning, abstract meaning and specific meaning, or literal meaning and figurative meaning. Phenomenon of polysemy confuses English learners hence ambiguity appears[5].

\section{Relation of Primary Meaning and Derivative Meaning}

Primary meaning is the basic meaning, or the first meaning. Derivative meaning is the extended meaning, or the second meaning.

Pupil means someone who is being taught, especially a child, and at the same time means the small black round area in the middle of your eye. The two meanings originate from one word, but completely different from each other. The word pupil comes from Latin, whose basic meaning is the small black round area in the eye. Ancient Romans saw their images were always little. Children were little; they naturally went to school, so they were called pupils.

As a noun, scale means the size or level of something, or the amount that something is happening; as a verb it means to climb to the top of something that is high and difficult to climb. In ancient times, people used to scratch scale on door frames to record their heights, which had the primitive role of "scales and measures". The higher the scale of the measure was, the heavier that something was weighed, and the larger the size to what is happening. Automatically scale had the meaning of the size to what is happening. In the old times without tools, people had to climb a high mountain by means of carving scales on the precipices and withholding the deeply-cut scales. So scale has the meaning of "climbing".

Convention is a core word in the postgraduate entrance exams, which appears in a high frequency. However it has three completely different meanings: general meeting, agreement, and routine. This word has a literary quotation. The basic meaning of convention is that people come together for assembly. The 13 initial governors of America went together to Philadelphia for a convention which distinguished from small meeting and press conference. In order to be free from British colonial rule, they convened in Philadelphia for the second continental congress, and signed a common convention (agreement), which was later named Declaration of Independence. Coherently, the day of signing the convention was Forth of July. According to the convention (routine), this date was designed to be Independence Day

\section{Relation of Universal Meaning and Special Meaning}

Universal meaning means general reference whereas special meaning means specific reference. Some words not only refer to general things but also refer to a specific thing of the general things.

Gas generally means a substance such as air, which is not solid or liquid, and usually cannot be seen while it specifically refers to a clear substance like air that is burned for heating or cooking such as petroleum. 


\section{Relation of Specific Meaning and Abstract Meaning}

Specific meaning and abstract meaning are the outcome of the change of meaning range of a word.

Ear's specific meaning is the organ of hearing, but its abstract meaning is sympathetic attention or notice, such example is that "She caught the minister's ear and persuaded him to accept her plan."

\section{Relation of Literal Meaning and Figurative Meaning}

Many English words have figurative meanings which make the language more vivid.

Green's literal meaning is the color of grass or leaves. Figurative meaning "without experience or training" is endowed to green now in the example like a green hand and a green recruits.

\section{Ambiguity Caused by Idioms}

Idiom refers to a group of words that has a special meaning that is different from the ordinary meaning of each separate word. All the idioms have their own origins. They almost originate from Holy Bible, literature, customs, and historical or political events, which are unfamiliar to English readers leading to ambiguity.

\section{Idioms from Holy Bible}

Britain is a religious country for a long history so English has been influenced by religion a lot especially by Holy Bible.

David and Jonathan is quoted from the story (Samuel I, 20:16,17,30). King Saul has a son called Jonathan. He is the good friend of David, and often protects David from Saul. When Saul knows that he was deserted by God, and sees that David is more powerful than him, it occurs to him that he wants to kill David so that the throne can be passed on to his son smoothly. But Jonathan informs David of his father's secret. Saul is full of ire when he finds his son betrays him. David and Jonathan is interpreted as close friends, who can even sacrifice himself for the other part, rather than two specific persons.

Benjamin's mess means the lion's share or the largest share of something when it is divided. The phrase is quoted from "And he took and sent messes unto them from before him: but Benjamin's mess was five times so much as any theirs." (Genesis 43:34)

\section{Idioms from Literature}

Many idioms come from literature especially from Shakespeare's works. The characters or plots in literature are typical and inspiring so they finally become idioms.

One's pound of flesh, meaning "something legal but unreasonable", originated from The Merchant of Venice. In this play, to help his friend with his proposal, Antonio borrowed money from the loan shark Shylock, covenanting to allow Shylock cut one pound of flesh from his body if he could not pay the debts when it is due. Unfortunately Antonio's merchant fleet wrecked causing him couldn't repay to Shylock, so Shylock asked Antonio to cut one pound of flesh by covenant.

Green-eyed monster, meaning “a jealouse person", quoted from Act III, Othello by Shakespeare:

O! Beware, my lord of jealousy;

It is the green-eyed monster 
which doth mock,

The meet it feeds on ...

\section{Idioms from Customs}

Language roots in life so formation of idioms must be influenced by customs.

Let one's hair down is an idiom meaning "to relax oneself". Previously, women were required to comb up their hair tidily on any occasion. Only alone could they let hair down to beome their true self.

Butter to butter is no relish doesn't mean certain food but "tiring sameness".

\section{Idioms from Historical or Political Events}

Interestingly the features of some events happening in the history are similar. It is easy for people to understand the feature of the later event with the help of previous one's just because they are familiar with it. So it is easy to understand E-mail Gate if you already know the event Watergate.

Keep one's powder dry means "be fully prepared". It is related to a story about Oliver Cromwell who was an English soldier and politician. During the campaign in Ireland, he delivered mobilization to his soldiers before attacking the enemy. After the battle was over, he said, "Put your trust in God; but be sure to keep powder dry".

\section{Counter Measures to Ambiguity}

Ambiguity is everywhere in each language. Learning English well lies on the following factors.

\section{Improving Cognitive Ability}

Cognitive ability is an ability of human brain to process, store and extract information. It is the most important psychological condition for people to perform successfully. English learners are supposed to take more communication with people, to read more books and more frequently keep in touch with today's various media. Accumulation of knowledge and experience is helpful to improve cognitive ability[6].

Cognitive ability can help English learners step over cultural barrier successfully. Different area has different culture which is reflected in languages. It is natural for English learners to encounter strange expressions in learning. Positive attitude is adopted when learners are confronted with ambiguity.

\section{Improving Ambiguity Tolerance}

Ambiguity intolerance was first introduced to the psychology discipline by the work of Frenkel Brunswik (1949) but has been further refined over the years. It refers to the "tendency to perceive or interpret information marked by vague, incomplete, fragmented, multiple, probable, unstructured, uncertain, inconsistent, contrary, contradictory, or unclear meanings as actual or potential sources of psychological discomfort or threat" (Norton, 1975) In other words, it is the "way an individual (or group) perceives and processes information about ambiguous situations or stimuli" (Furnham and Ribchester, 1995) [7]

Through research, Ely believes that ambiguity tolerance has remarkable influence on second language learning strategy [8]. Learners of low ambiguity tolerance tend to pay more attention to language details, which may lower the efficiency of language learning; whereas learners of high ambiguity tolerance lay particular emphasis on the entirety of language, which undoubtedly increase the efficiency of language learning. 
Furthermore, English learners should improve their learning style, preventing missing the wood for the trees. They are encouraged to guess meanings of new words according to the context instead of looking up dictionaries for each new word, which can slow down reading speed.

\section{Conclusions}

Ambiguity is a linguistic phenomenon existent in any language. It is the result of social development and language development. Second language learners should accept and face it. Research on ambiguity and its causes can be helpful not only to accept ambiguity, enhance deeper cognition on English, but also learn to use ambiguity to achieve unexpected effect. It is ambiguity that makes a language vivid and interesting. So English learners should take positive attitude towards ambiguity, make efforts to improve their cognitive ability and ambiguity tolerance so as to learn English in a high efficiency.

\section{References}

[1] Shou-ren Wang, Reading Course, Book 3, Shanghai Foreign Language Education Press, 2014, P197

[2] http://www.dawn.com/news/881055/us-china-changing-relationship, 2009

[3, 4]Helen Keller, If I Had Three Days in the Light

[5] Rong-pei Wang, [M] English Lexicology, Shanghai Foreign Language education Press, 2008, P98, 99

[6] Information on http://baike.so.com/doc/1915537-2026666.html

[7] Information on http://onlinelibrary.wiley.com/doi/10.1111/j.1467-6494.1962.tb 02303.x/references

[8] Ely, Ambiguity Tolerance on Second Language Learning Strategies [J] Modern Language Journal, 1989, (22); 437-45

[9] Longman Dictionary of Contemporary English, Longman 